\title{
Identifikasi Jenis Hijauan Makanan Ternak Di Lahan Persawahan Desa Babakan Kecamatan Dramaga Kabupaten Bogor
}

\author{
Nurlaha $^{1}$, Agus Setiana ${ }^{2}$ dan Nur Santy Asminaya ${ }^{3}$ \\ ${ }^{1)}$ Pascasarjana Institut Pertanian Bogor \\ ${ }^{2)}$ Fakultas Peternakan Institut Pertanian Bogor \\ ${ }^{3)}$ Fakultas Peternakan Universitas Haluoleo
}

\begin{abstract}
Forage is an animal feed ingredients derived from plants or grasses including legume that should be available continuously in terms of both quality and quantity. The forage availability vary by region depending on the location, climate, season, soil quality and so on. This study aims to determine the type of forage fodder that exist in the rice field near Green Dramaga housing. The method used is herbarium of forage methode namely exploration of collections herbarium by the Stone method (1983). The results of the identification showed that the location of rice fields and horticultural fields had 35 types of vegetation consisting of 16 types of grass, 6 types of legume and 12 types of rumba. Type of forage that dominate the area of rice fields and the horticultural fields is grasses with a percentage of $79.34 \%$, followed by the type of legume of $7.38 \%$ and rumba amounted to $13.28 \%$. The most dominant grass species on the rice fields and the horticultural fields is Paspalum Sp.
\end{abstract}

Keyword : Forage, Rice Field, Horticultura Field

\begin{abstract}
Abstrak
Hijauan adalah bahan pakan ternak yang diperoleh dari rumput termasuk legum yang harus tersedia secara berkelanjutan baik kualitas dan kuantitas. Ketersediaan hijauan bervariasi tergantung pada lokasi, cuaca, musim, kualitas tanah dan sebagainya. Penelitian ini bertujuan untuk mengidentifikasi jenis dari hijauan yang terdapat pada areal sawah dan tanaman palawija. Metode yang digunakan adalah herbarium hijauan dengan mengeksplorasi koleksi pada herbarium berdasarkan metode Stone (1983). Hasil identifikasi menunjukan lokasi areal persawahan dan areal palawija memiliki 35 jenis vegetasi yang terdiri atas 16 jenis rumput, 6 jenis legum dan 12 jenis rumba. Jenis hijauan yang mendominasi areal persawahan dan palawija adalah rumput dengan persentasi $79,34 \%$, diikuti oleh legum 7,38\% dan rumba $13,28 \%$. Jenis rumput yang paling dominan adalah jenis Paspalum Sp.
\end{abstract}

Kata kunci : Hijauan, Sawah, Palawija 


\section{PENDAHULUAN}

Hijauan pakan ternak adalah semua bentuk bahan pakan berasal dari tanaman atau rumput termasuk leguminosa baik yang belum dipotong maupun yang dipotong dari lahan dalam keadaan segar (Akoso, 1996) yang berasal dari pemanenan bagian vegetatif tanaman yang berupa bagian hijauan yang meliputi daun, batang, kemungkinan juga sedikit bercampur bagian generatif, utamanya sebagai sumber makanan ternak ruminansia (Reksohadiprodjo, 1985). Untuk penanaman hijauan makanan ternak dibutuhkan tanah yang subur dan memenuhi persyaratan-persyaratan jenis tanah dan iklim yang sesuai dengan yang dikehendaki (Sosroamidjoyo dan Soeradji, 1986).

Identifikasi genus/spesies hijauan pakan semakin penting dilakukan mengingat semakin pentingnya arti hijauan pakan bagi kebutuhan ternak. Identifikasi hijauan pakan khususnya rumput dapat dilakukan berdasarkan pada tanda-tanda atau karakteristik vegetatif (Reksohadiprodjo, 1985). Termasuk kelompok makanan hijauan ini ialah bangsa rumput (graminae), leguminosa dan hijauan dari tumbuh-tumbuhan lain seperti daun nangka, daun waru dan lain sebagainya (AAK, 1983). Menurut Nell dan Rollinson (1974), produksi rumput yang tumbuh di tanah sawah, tegalan, kebun, hutan dan pinggir jalan berkisar antara 14-15 ton bahan kering (BK)/ha/tahun, sedangkan untuk padang pangonan sekitar 1,5 ton dan kebun rumput sekitar 2,5 ton BK/ha/tahun.

\section{METODE PENELITIAN}

\section{Tempat dan Waktu Pelaksanaan}

Penelitian dilaksanakan di areal persawahan dekat perumahan Dramaga Hijau. Lokasi ini ditentukan secara senganja.

\section{Materi}

Materi penelitian adalah hijauan makanan ternak yang tumbuh di areal pematang sawah desa Babakan kecamatan Dramaga. Peralatan yang digunakan berupa kuadran (disesuaikan dengan luas pematang sawah yang ada dengan panjang pengamatan 1 meter), caunter, pisau kantong plastik, alat tulis, alkohol $70 \%$, kertas buram, label dan GPS device.

\section{Identifikasi Jenis Hijauan}

Identifikasi jenis hijauan menggunakan metode herbarium hijauan pakan dengan mengikuti metode Stone (1983) yaitu eksplorasi koleksi herbarium. Pembuatan herbarium basah yaitu dengan cara mengambil satu helai tiap jenis hijauan lalu disemprotkan alkohol $70 \%$ pada seluruh bagian tanaman, kemudian diletakkan pada kertas koran yang ditutup secara rapat, lalu diikat dengan tali. Seluruh data lapangan dalam spesimen dikoleksi dicatat.

\section{Pengambilan Sampel}

Sampel diambil dari lokasi sawah (sistem tanam tumpang sari padipalawija) di desa Babakan. Untuk pengambilan sampel lokasi diklaster menjadi dua bagian yaitu areal sawah dan areal tanaman palawija. Pengambilan sampel dilakukan dengan metode tracking di pematang sawah dan disekitar tanaman palawija untuk mengamati semua jenis rumput. Rumput diambil dalam keadaan berbunga agar memudahkan proses identifikasi kemudian dikoleksi, dijadikan herbarium dan selanjutnya dibawa ke Laboratorium Agrositologi Institut Pertanian Bogor untuk diidentifikasi sehingga dapat dikelompokkan berdasarkan jenisnya. Pengambilan sampel dilakukan pada awal pengolahan sawah.

Setelah dilakukan identifikasi jenis rumput, legum dan rumbah yang ditemukan di lokasi tersebut, dilanjutkan 
dengan pendugaan komposis botani jenis hijauan yang ada pada pematang sawah dan dirangking dan ditabulasi untuk melihat komposisi botani. Pengambilan cuplikan sampel dilakukan sebanyak 50 cuplikan. Sepuluh jenis hijauan yang dominan dicatat untuk mengetahui tingkat dominasi vegetasi tersebut. Pengamatan komposis botani ini dilakukan setelah padi berbuah atau sebelum dipanen.

\section{HASIL DAN PEMBAHASAN}

\section{Analisis Vegetasi Hijauan}

Hasil pengamatan dilapangan menunjukkan bahwa di pematang sawah dan lokasi tanaman hortikultura ada beberapa golongan graminae dan syparese dapat dimanfaatkan sebagai hijauan makanan ternak sebagaimana terlihat di bawah ini;

\section{Jenis Rumput (Graminea)}
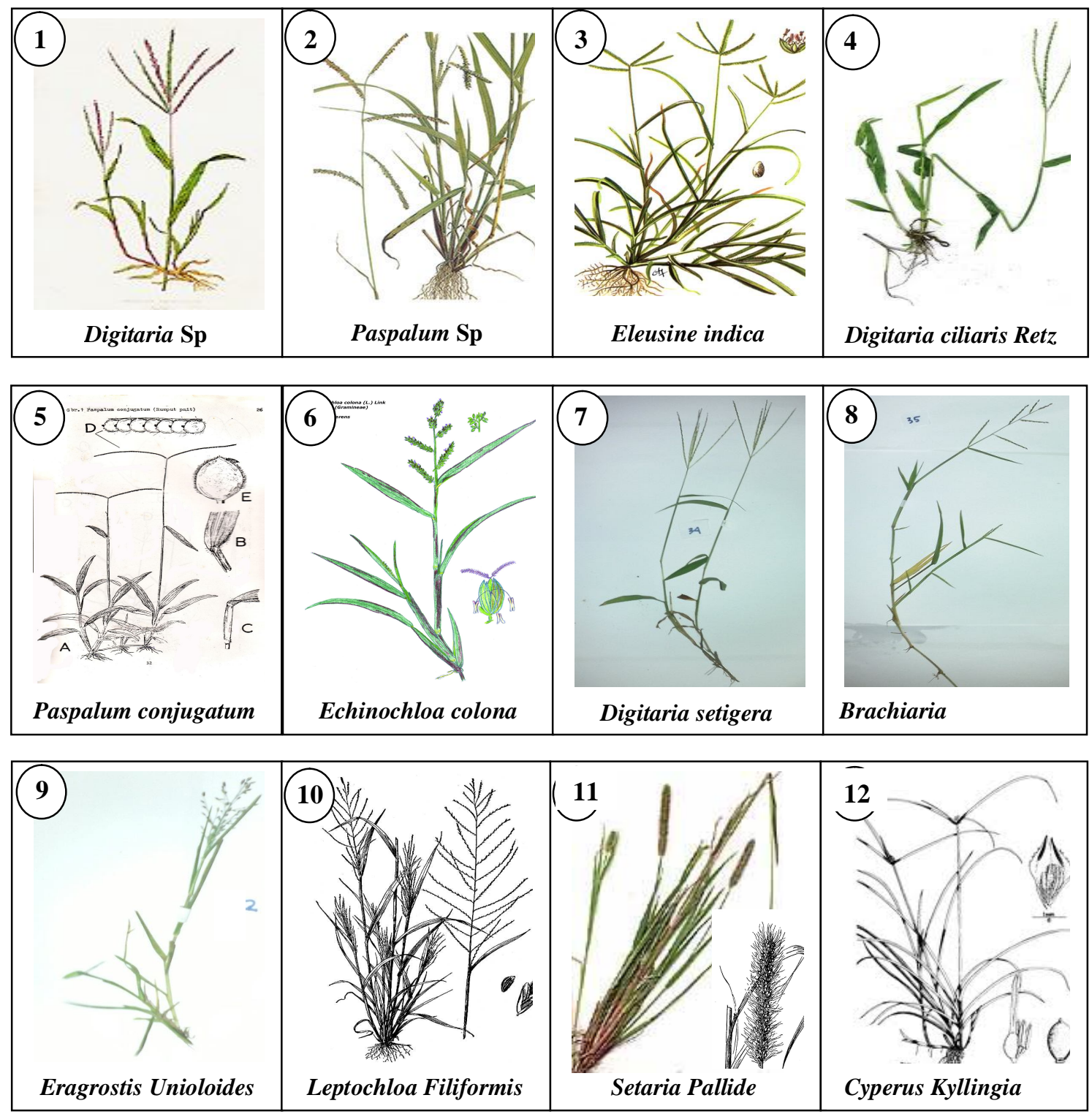


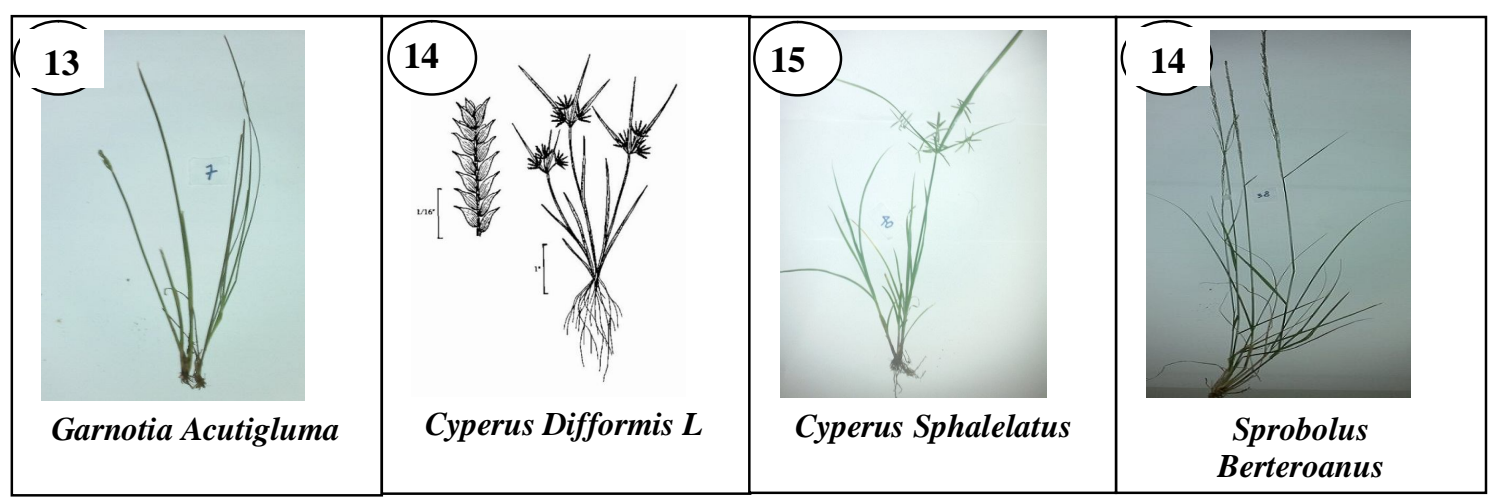

\section{Jenis Leguminosa}
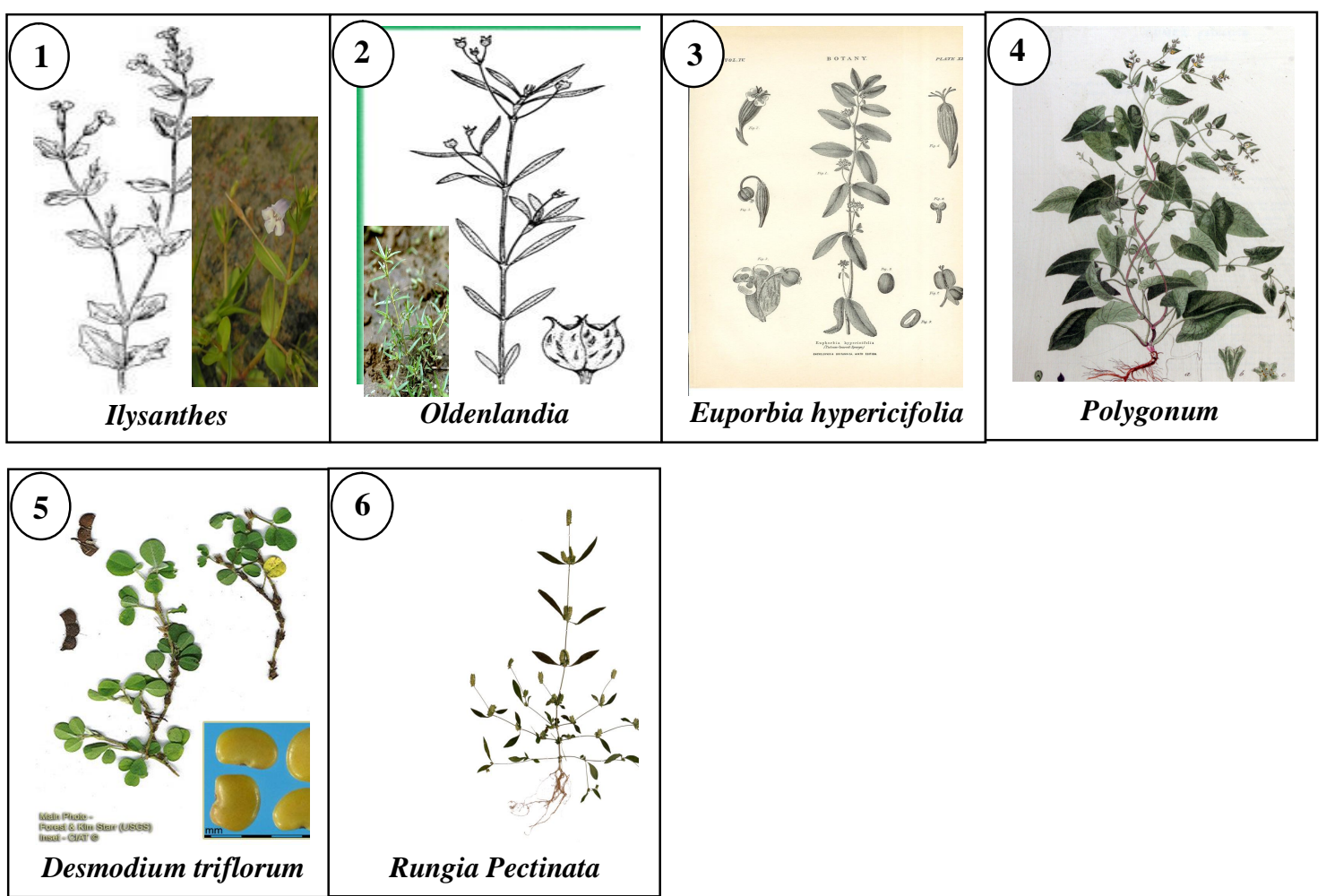

\section{Jenis Rumba}

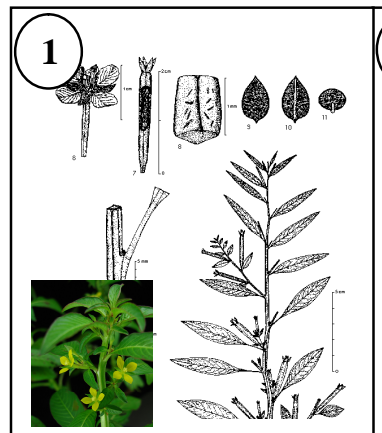

Ludwigia hyssopifolia

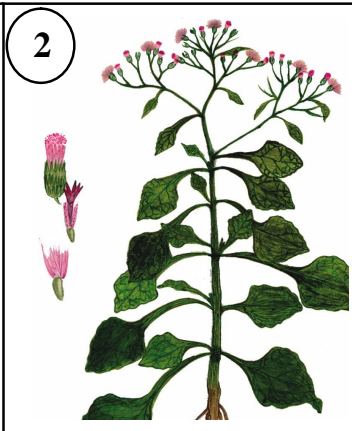

Vernonia cinerea

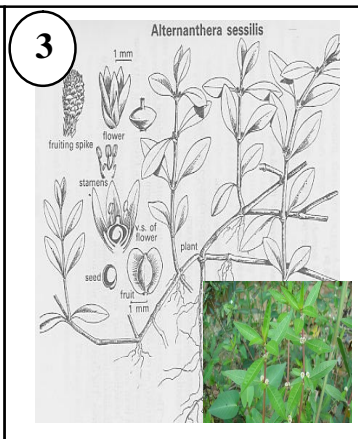

Alternanthera sissilis

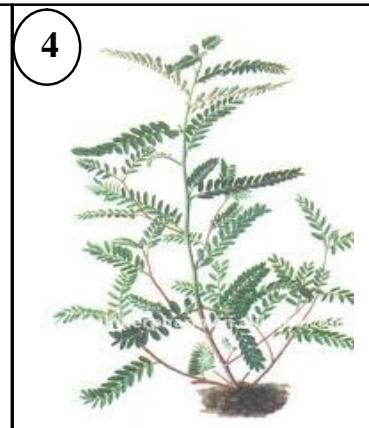

Phyllantus minuri 

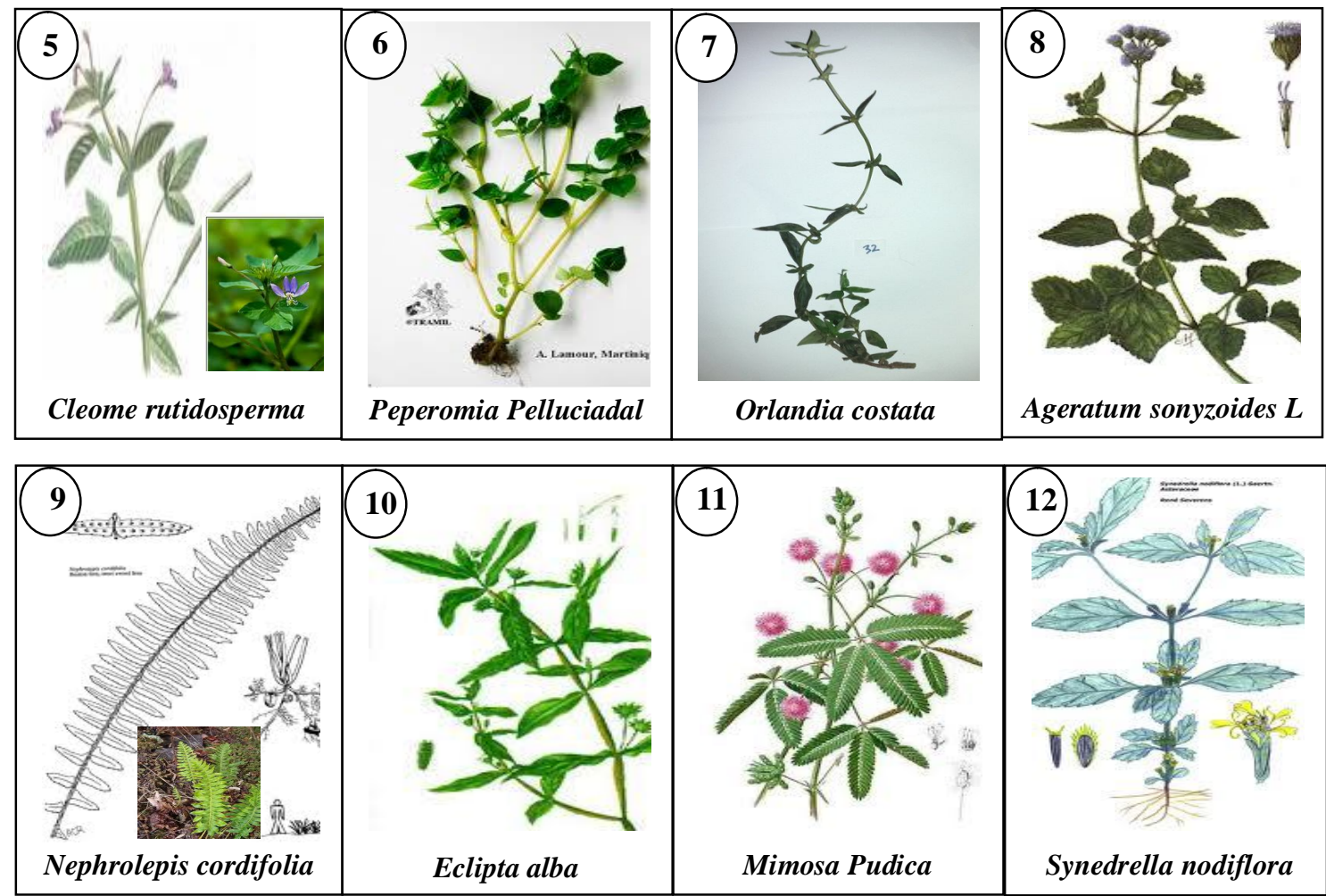

Hasil identifikasi hijauan makanan ternak dilapangan menunjukkan bahwa di pematang sawah dan lokasi tanaman hortikultura terdapat 35 jenis vegetasi tanaman yang terdiri dari 16 jenis rumput, 6 jenis leguminosa dan 12 jenis rumba. Berdasarkan hasil pengamatan jenis rumput paling mendoninasi vegetasi tersebut. Hal ini menunjukkan bahwa pada areal pematang sawah dan lokasi tanaman hortikultura berpotensi sebagai penyediaan hijauan makanan ternak khususnya ternak ruminansia.

\section{Analisis Komposisi Botani}

Tothlill et al., (1992) menyatakan bahwa ada beberapa metode untuk

mengetahui komposisi botani, yaitu : a) Pemisahan dengan tangan dan penimbangan hijauan pakan yang telah dipotong; b) Estimasi persentase berat pada hijuan pakan yang telah dipotong; c) Estimasi persentase berat in situ di kebun atau di lapangan; dan d) Estimasi unit berat dari tiap-tiap spesies di kebun atau lapangan.

Hasil perangkingan terhadap rumput, legum dan rumba yang diamati di lapangan memperlihatkan jenis rumput sebagai komposisi botani yang paling dominan kemudian disusul oleh jenis leguminosa dan rumba

Tabel 2. Komposisi Botani Hijauan Pematang Sawah

\begin{tabular}{cc}
\hline Jenis Vegetasi & Komposis Botani (\%) \\
\hline Rumput & 79,34 \\
Legum & 7,38 \\
Rumba & 13,28 \\
\hline
\end{tabular}


Data tabel memperlihatkan rumput sangat mendominasi areal pematang sawah dan lokasi tanaman hortikultura dengan persentase rumput sebesar 79,34\%, kemudian diikuti oleh jenis leguminosa sebesar $7,38 \%$ dan rumba sebesar $13,28 \%$. Jenis rumput yang ditemukan di areal pematang sawah dan lokasi tanaman hortikultura adalah Paspalum Sp., Digitaria Sp., Brachiaria Sp., Eleusine Indica, Echinochloa Colona, Eragrostis Unioloides, Leptochloa Sp, Cyperus Sp., Setaria Sp, Garnotia Acutigluma dan Sprobolus Berteroanus.

Menurut Ugiansky (2010), jenis Paspalum Sp. umumnya ditemukan tumbuh di daerah berumput dan bukaan kayu pada daerah dataran rendah, lembab, tanah berpasir dan sepanjang rawa payau. Digitaria Sp. umumnya ditemukan di daerah padang rumput, lembab dataran rendah, tempat basah, tempat kering, berpasir, tanaman hortikultura dan pertanian (Uva et al., 2010). Brachiaria Sp umumnya ditemukan pada tempat-tempat sampah, lahan pertanian, hutan terbuka, padang rumput, pinggir jalan, hutan lembab, pesisir, tepi rawa, di sepanjang anak sungai, sungai tergenang musiman dan saluran sungai (Ghazanfar et al. 2001). Eleusine Indica merupakan jenis tanaman yang tahan kekeringan dan herbisida digolongkan sebagai gulma pada tanaman budidaya dan lapangan golf, dapat tumbuh dengan subuh di tanah padat dan di bawah sinar matahari penuh (Ivens, 1989). Echinochloa Colona umumnya tumbuh di daerah rawa dan padang rumput (FAO, 2002), di sawah irigasi dan lahan perkebunan, aliran sungai, tempat sampah dan pekarangan (Maun dan Barrett, 1986). Leptochloa Sp berkembang di habitat yang lembab, di sepanjang surut waduk, irigasi, dibudidayakan, lahan ternak, bersama aliran air dan di sepanjang jalan raya (Snow and Peterson 1992). Kebanyakan spesies Eragrostis menempati habitat terbuka dengan tanah yang miskin, dan distribusinya hingga mencapai $3600 \mathrm{~m}$ dari permukaan laut (Peterson and Cannas, 2010). Cyperus Sp umumnya terdapat di daerah berpasir, daerah sekitar gurun, daerah kering yang ekstrim dan dipinggir pantai (Vare and Kukkonen, 2005). Setaria Sp cocok di daerah tropis lembab, daerah irigasi, tidak mudah adaptasi pada tanah alkali, sangat asam atau saline (Cook, 2007). Garnotia Acutigluma umumnya ditemukan pada tanah berbatu di lereng gunung, dekat sungai, tempat-tempat teduh dan hutan lebat hingga ketinggian $1700 \mathrm{di}$ atas permukaan laut (Zhenland and Philip, 2006).

Jenis leguminosa yang terdapat pada areal pematang sawah dan lokasi tanaman hortikultura diantaranya Ilysanthes, Oldenlandia Carymbola, Euporbia hypericifolia, Rungia Pectinata, Polygonum convolvolus dan Desmodium triflorum. Habitat yang paling disukai oleh Ilysanthes adalah tempat yang cerah di bawah peneduh, tempat berpasir dan dapat mentolerir rendaman selama beberapa hari, ditemukan di sawah, pinggir jalan hingga 1.500 di atas permukaan laut (Randal, 2002). Oldenlandia Carymbola merupakan tanaman yang hidup di daerah terbuka hingga 1.500 di atas permukaan laut termasuk di pinggir jalan, kebun, tanah garapan, padang rumput, hutan terbuka dan daerah pinggiran sungai (Randal, 2002). Euporbia hypericifolia dapat ditemukan di sepanjang pinggir jalan, di lereng bukit, padang rumput, dan tanah kering berpasir. Rungia Pectinata umumnya hidup di daerah aliran sungai, tanah lembab, di hutan lebat, gunung berbatu, bukit dan lembah (Jiaqi et al., 2011). 
Tabel 3. Persentasi Jenis Rumput yang mendominasi Pematang Sawah pada Saaat Padi berbuah

\begin{tabular}{lc}
\hline \multicolumn{1}{c}{ Spesies } & Dominasi $(\%)$ \\
\hline Digitaria sp & 17,65 \\
Paspalum sp & 11,76 \\
cyperus kyllingia Endl & 10,29 \\
Eleusine Indica & 10,29 \\
Paspalum vonjugatum & 8,82 \\
Eragrostis unioloides & 7,35 \\
Brachiaria subquadripara & 7,35 \\
Cyperus difformis L & 7,35 \\
Echinochcoa colona & 5,88 \\
Castoria acutigluma Ohwi & 4,41 \\
\hline
\end{tabular}

Polygonum convolvolus umumnya terdapat di pinggir jalan, tanah dumping dan sering digunakan sebagai tanaman penutup tanah dan Desmodium triflorum terdapat dalam berbagai bentuk hutan dan lahan limbah dan dapat hidup $5.000 \mathrm{~m}$ di atas permukaan tanah (Kirubha, 2011).

Jenis rumba yang ditemukan pada areal pematang sawah dan lokasi tanaman hortikultura diantaranya Ludwigia hyssopifolia, Vernonia cinerea, Alternanthera sissilis (L.)R.E, Peperomia Pelluciadal, Phyllantus minuri, Cleame rutidosperma, Agetatum Conyzoides L, Nephrolepis cordifolia, Eclipta alba, Mimosa Pudica, Synedrella nodiflora dan Orlandia Castuto. Ludwigia hyssopifolia banyak ditemukan di perairan dangkal, habitat air tawar, termasuk kolam, rawa dan parit, juga tumbuh di tanaman irigasi, kebun, tanah kosong, pinggir jalan, pembukaan hutan, padang rumput dan daerah lembab (Randal, 2002). Vernonia cinerea, Alternanthera sissilis (L.)R.E umumnya ditemukan di pinggir jalan, lahan kosong, daerah perkotaan hijau, taman, kebun, tanah yang subur, lahan basah, lapangan terbuka dan perkebunan serta lahanbasar pesisir, Peperomia Pelluciadal merupakan herba yang ditemukan tumbuh subur di tanah lembab di bawah naungan pohon dan berkembang di sepanjang musim hujan (Majumder, 2011), Phyllantus minuri tumbuh liar di tanah datar dan daerah pegunungan hingga tinggi sampai $1000 \mathrm{~m}$ dari permukaan laut, di tempat terbuka pada tanah gembur dan berpasir, ladang, tepi sungai dan pantai, bahkan di sekitar pekarangan rumah (Dalimarta, 2000). Cleame rutidosperma umumnya terdapat di lahan kosong, lapangan limbah, pinggir jalan dan ditemukan di seluruh daerah tropis (Azis and Shaukad, 2012). Ageratum Conyzoides $L$ tumbuh di dekat pemukiman, tanah kebun, di tempat sampah (Okunade, 2002). Nephrolepis cordifolia gemar hidup subur di kawasan lembab dan hutan (Meiden, 2011). Eclipta alba umumnya ditemukan pada dataran tinggi, kebun, sepanjang tepi saluran air, pinggir jalan yang agak lembab dan limbah tempat basah (Umemoto and Koyama, 2007). Mimosa Pudica tumbuh di tanah kosong, pinggir jalan, kebun dan sebagai penutup tanah (Varnika et al., 2012). Synedrella nodiflora umumnya tumbuh di tempat lembab, teduh, nutrisi tanah yang kaya dan sebagai gulma pada tanaman tropis (Filho and Takaki, 2011).

Persentasi jenis rumput yang mendominasi pematan sawah pada saat padi berbuah didominasi oleh Digitarium Sp $(17,65 \%)$ kemudian disusul oleh Paspalum (11,76\%); Cyperus kyllingia Endl dan Eleusine Indica (10,29\%); Paspalum vonjugatum (8,82\%); 
Eragrostis unioloides, Brachiaria subquadripara dan Cyperus difformis L (masing-masing sebesar 7,35\%); Echinochcoa colona $(5,58 \%)$ dan Castoria acutigluma Ohwi $(4,41 \%)$.

\section{KESIMPULAN}

Pada pematang sawah dan lokasi tanaman hortikultura terdapat 35 jenis vegetasi tanaman yang terdiri dari 16 jenis rumput, 6 jenis leguminosa dan 12 jenis rumba. Rumput merupakan jenis hijauan yang mendominasi areal pematang sawah dan lokasi tanaman hortikultura dengan persentase sebesar $79,34 \%$, kemudian diikuti oleh jenis leguminosa sebesar $7,38 \%$ dan rumba sebesar $13,28 \%$. Jenis rumput yang paling dominan pada petang sawah dan lokasi tanaman hortikultura adalah Paspalum Sp.

\section{DAFTAR PUSTAKA}

Akoso, B.T. 1996. Kesehatan Sapi. Kanisius, Yogyakarta.

AAK. 1983. Hijauan Makanan Ternak Potong, Kerja dan Perah. Yayasan Kanisius, Yogyakarta.

Cook, B.G. 2007.Pasture Autralia. A collaboration between AWI, GRDC, MLA, RIRDC and Dairy Australia. Tropical Forages database (SoFT) - SetariaNSW Deprtment of Primary Industries Setaria Agnote DPI-293

Dalimarta, S. 2000. Atlas Tumbuhan Obat Indonesia. Trubus, Agriwidya: Bogor.

FAO. 2002. Echinochloa colona (L.) Link. Grassland Index. Htpp://www.fao.org/weincent/faoin fo/agricult/agp/agpc/doc/gdata/data

Filho, PRM. and Takaki, M. 2010. Dimorphic cypsela germination and plant growth in Synedrella nodiflora (L.) Gaertn. (Asteraceae). Departamento de Botânica, Laboratório de Fotomorfogenese de Plantas, Instituto de Biociências,
Universidade Estadual Paulista "Júlio de Mesquita Filho" UNESP, Brazil.

Ghazanfar, S.A., Keppel, G. \& Khan, S. 2001. Coastal vegetation of small islands near Viti Levu and Ovalan, Fiji. New Zealand Journal of Botany 39: 587-600.

Ivens G. W. 1989. East Africans weeds and their control. Oxford University Press, Tanzania.

Jiaqi, S.H., D. Yunfei and T. F. Daniel. Rungia A Nees in Wallich. Fl. China 19: 443-447. 2011.

Kirubha, S.V., M. Jegadeesan and S. Kavimani. 2011. Studies on Desmodium gangeticum: A review J. Chem. Pharm. Res 3(6):850$855 \mathrm{~T}$.

Maideen, H., Z.C.DESA, A. DAMANHURI. 2011. Kepelbagaian dan Habitat Pteridofit di Hutan Simpan Angsi, Negeri Sembilan (Diversity and Habitat of Pteridophytes in Angsi Forest Reserve, Negeri Sembilan). Sains Malaysiana 40(12): 1341-1344.

Majumder,P., P. Abraham and Satya. 2011. Ethno-medicinal, Phytochemical and Pharmacological review of an amazing medicinal herb Peperomia pellucida (L.) HBK. Research Journal of Pharmaceutical, Biological and Chemical science.

Maun, M.A dan Barrett, S.C.H. 1986. The Biology of Canadian Weeds 77 Ivens G. W. 1989. East Africans weeds and their control (Echinochola cruss galli (L). Beauv. Can. J. Plant Sci 66:739759.

Nell, J.A dan D.H.L. Rollinson. 1974. The Requirements and Availability of Livestock Feed in Indonesia, Jakarta.

Okunade, A.L. 2001. Ageratum conyzoides L. Asteraceae J.Fitoterapia 73:1-16 
Peterson, P.M., D. Giraldo-Canas. Investigacion, Biodiversidad $\mathrm{y}$ Desarrollo 2010; 29 JJ.-5-11

Randall, R.P. 2002. A Global Compendium of Weeds; Shannon Books, Australia. , Pl. Asiat. Rar. 3: 77, 109. 1832.

Reksohadiprodjo, S. 1985. Produksi Tanaman Hijauan Makanan Ternak tropic. Edisi Kedua. BPFE. Universitas Gadjah Mada, Yogyakarta Siregar, S.B. 1994. Ransum Ternak Ruminansia. PT. Penebar Swadaya, Jakarta.

Uva,R., J. Neal and J.D.Tomaso. 2010. Text and Picture: Weeds of the Northeast.http://commodities.caes.u ga.edu/turfgrass/georgiaturf/Weed Mngt/grsweedpages/

Snow, N. \& Peterson, P. M. (1992). Noteworthy Collections: Nevada. Madroño 39: 158. Contribuciones Para Una Monografia De Las Especies Americanas De Eragrostis (Poaceae: Chloridoideae: Eragrostideae): Novedades Para Colombia, Mexico Y Peru

Sosroamidjojo, M.S dan Soeradji. 1986. Peternakan Umum. CV. Yasaguna, Jakarta.

Stone, B.C. 1983. A Guide To Collecting Pandanaceae (Pandanus, Freycinetia, Sararanga). Ann Missouri Bot. Gard. 70 : 137-14.

Ugiansky, R. 2010. Plant guide for Florida paspalum (Paspalum floridanum). USDA-Natural Resources Conservation Service, Norman A. Berg National Plant Materials Center. Beltsville.

Umemoto, S and H. Koyama. 2007 Thai for. Bull. (bot.) 35: 108-118.

Vare, H dan I. Kukkonen. 2005. Seven New Species of Cyperus (Cyperaceae) section Arrenarri and One New Combination and Typication. Ann Bot Fenicci 42 : 473-483
Varnika, S., S. Ashish and A.Imran. 2012. A Review On Ethnomedicaland Traditional Usesof Mimosa Pudica(Chui-Mui). Department Of Pharmacy, Suresh Gyan Vihar University, Rajasthan, India 3 (2)

Zhenlan W., S.M. Phillips. Garnotia. Flora of China 22: 562-563. 2006. 